\title{
Regioselective Synthesis of Methyl-Substituted Adamantanes for Promoting Oxidation Stability of High-Density Fuel
}

Jiawei Xie ${ }^{\mathrm{a}, \mathrm{b}, \dagger}$, Yi Liu ${ }^{\mathrm{a}, \mathrm{b}, \dagger}$, Tinghao Jia ${ }^{\mathrm{a}, \mathrm{b}}$, Lun Pan ${ }^{\mathrm{a}, \mathrm{b}}$, Yunming Fang ${ }^{\mathrm{c}}$, Chengxiang Shi ${ }^{\mathrm{a}, \mathrm{b}}$, Genkuo $\mathrm{Nie}^{\mathrm{a}, \mathrm{b}}$, Xiangwen Zhang ${ }^{\mathrm{a}, \mathrm{b}}$ and Ji-Jun Zou ${ }^{\mathrm{a}, \mathrm{b}, *}$

a. Key Laboratory for Green Chemical Technology of Ministry of Education, School of Chemical Engineering and Technology, Tianjin University, Tianjin 300072, China.

b. Collaborative Innovation Center of Chemical Science and Engineering (Tianjin), Tianjin University, Tianjin 300072, China.

c. National Energy R\&D Research Center for Biorefinery, Department of Chemical Engineering, Beijing University of Chemical Technology, Beijing 100029, China.

* Corresponding author at: Key Laboratory for Green Chemical Technology of Ministry of Education, School of Chemical Engineering and Technology, Tianjin University, Tianjin 300072, China.Tel and fax: 86-22-27892340._E-mail address:jj_zou@tju.edu.cn (Ji-Jun Zou).

$\dagger$ The authors contributed equally to this work. 


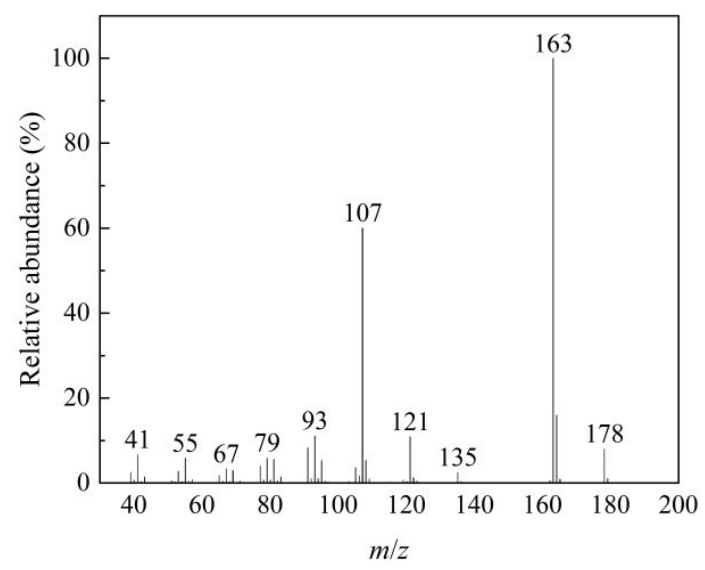

Figure S1. Mass spectra of 1,3,5-trimethyl-adamantane.

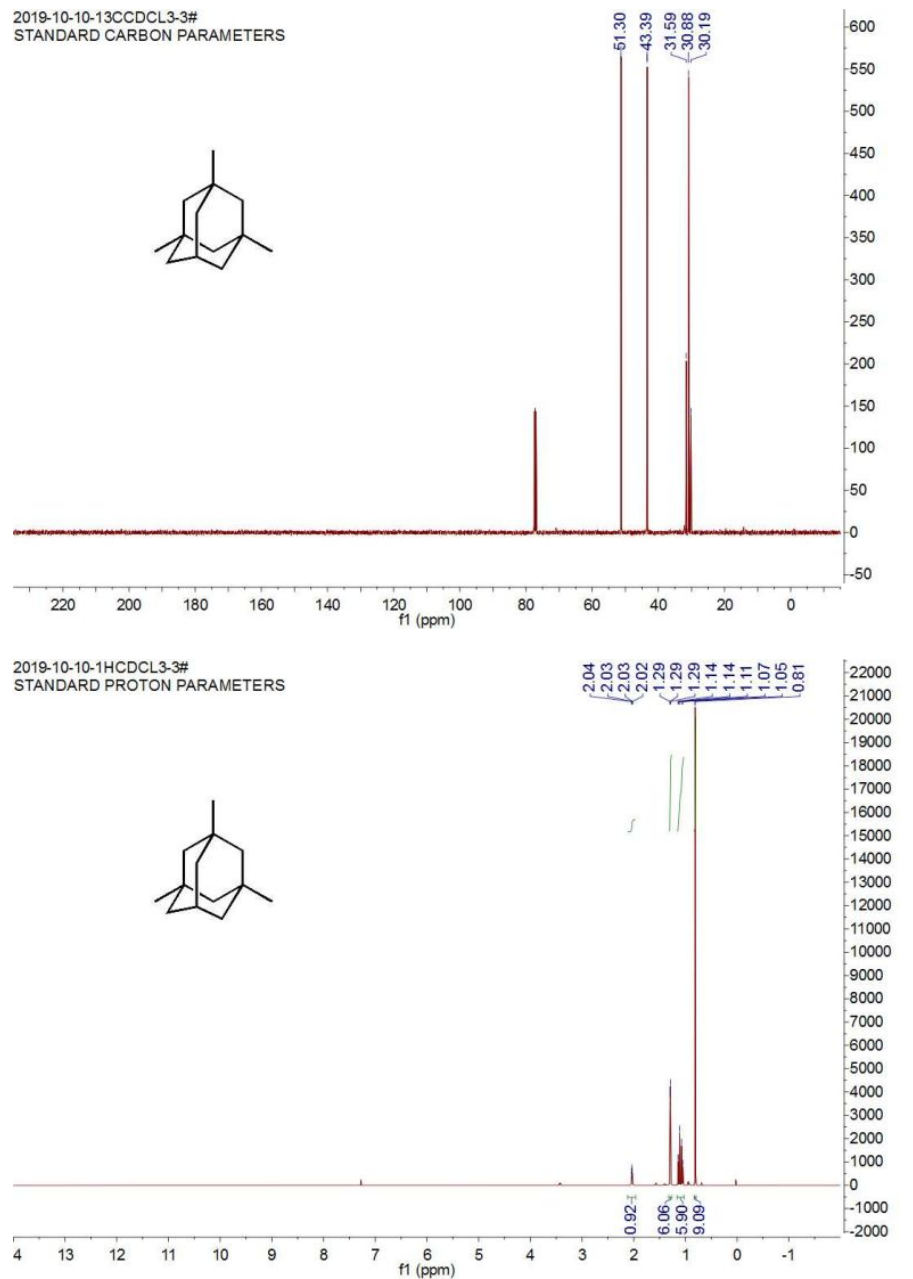

Figure S2. ${ }^{1} \mathrm{H}$ and ${ }^{13} \mathrm{C}$ NMR spectra of 1,3,5-trimethyl-adamantane. 


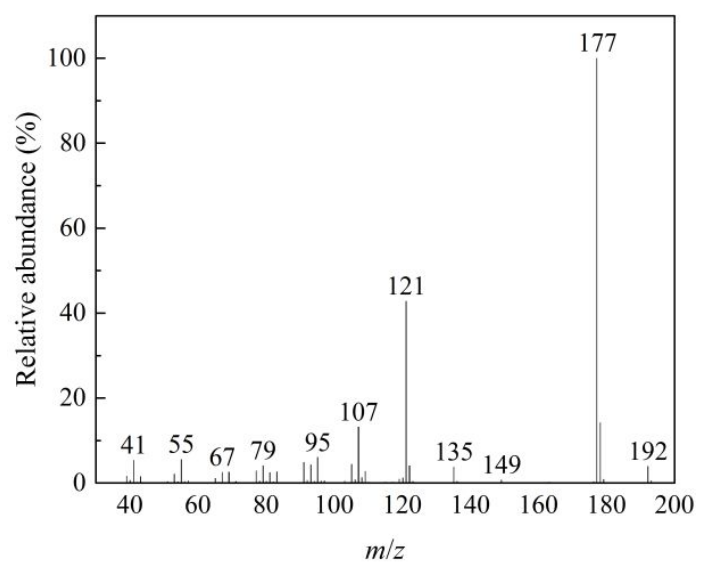

Figure S3. Mass spectra of 1,3,5,7-tetramethyl-adamantane.

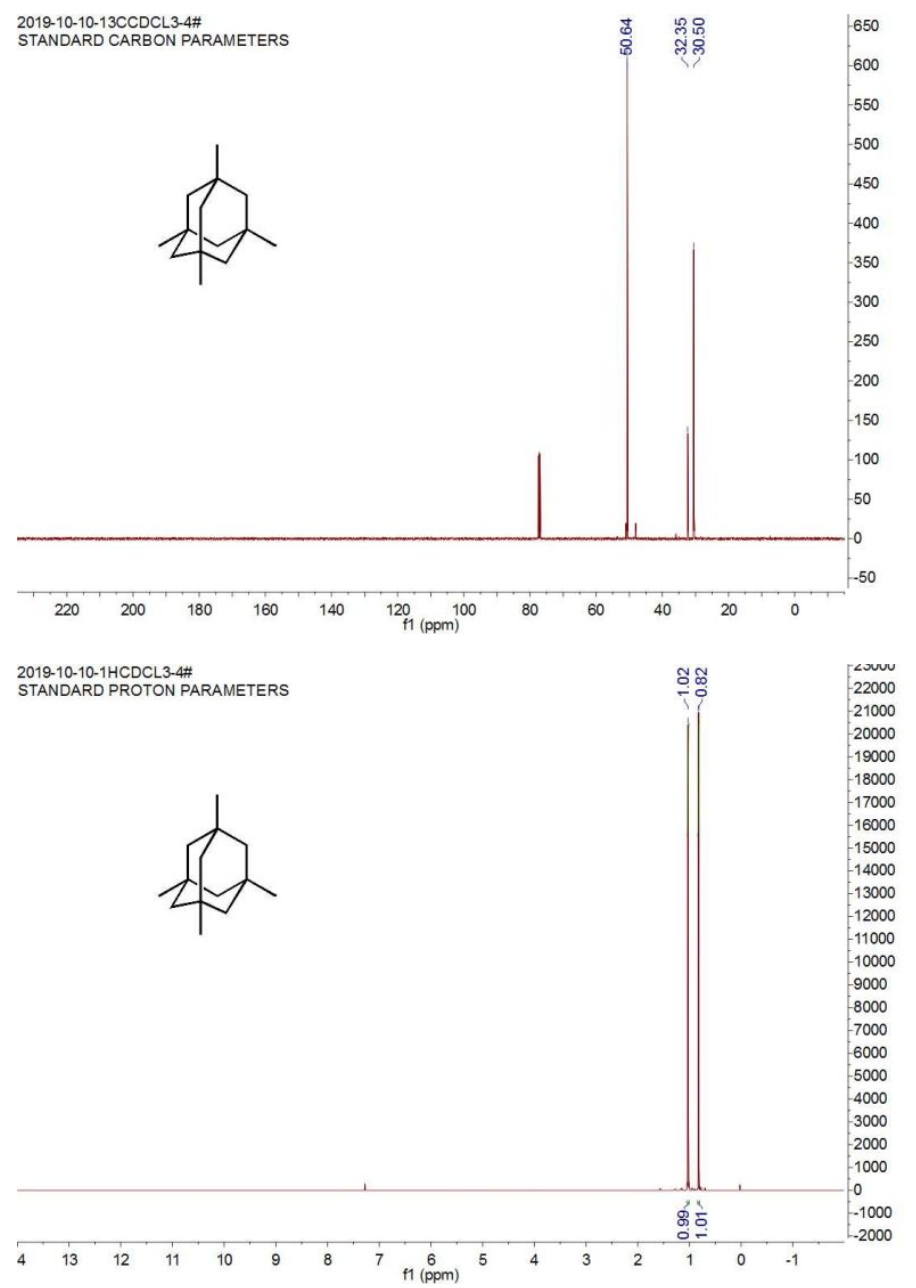

Figure S4. ${ }^{1} \mathrm{H}$ and ${ }^{13} \mathrm{C}$ NMR spectra of 1,3,5,7-tetramethyl-adamantane. 


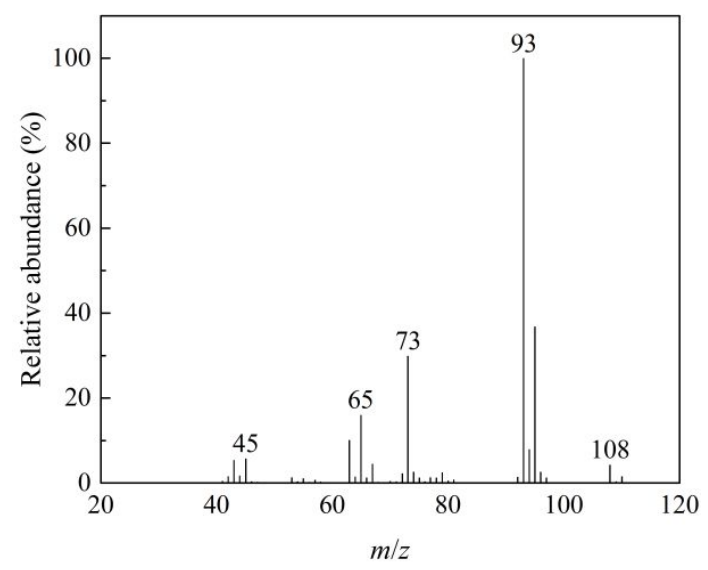

Figure S5. Mass spectra of chloro-trimethyl-silane.

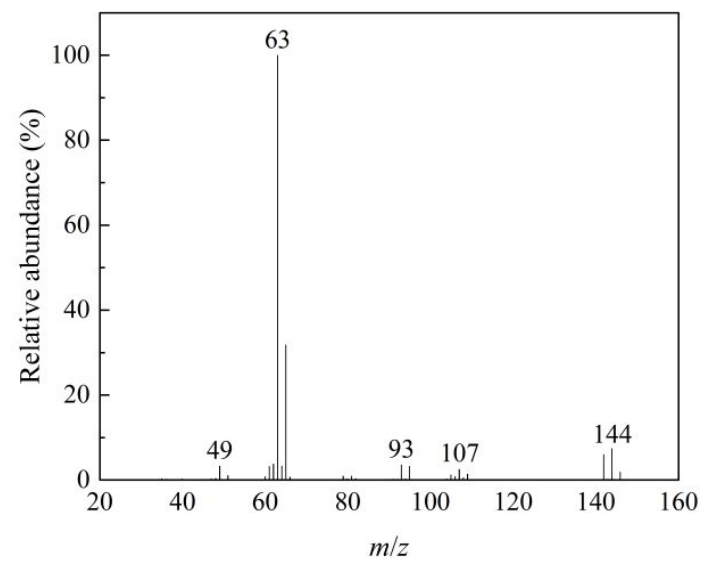

Figure S6. Mass spectra of 1-bromo-2-chloroethane.

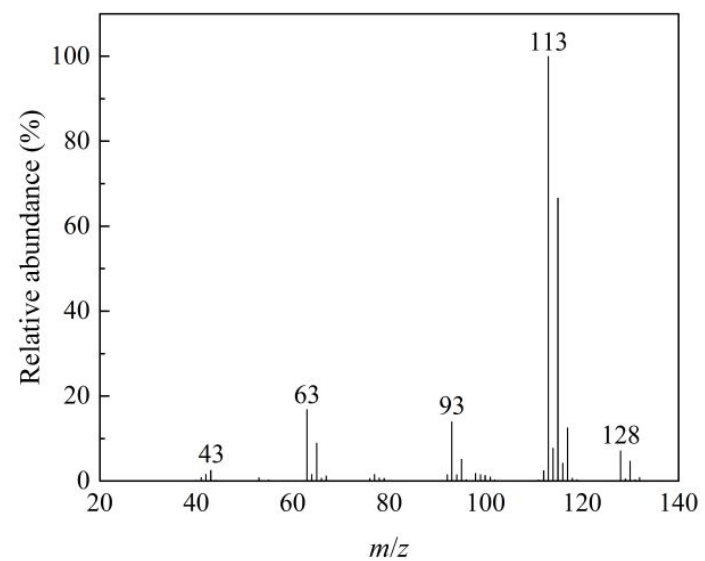

Figure S7. Mass spectra of dichloro-dimethyl-silane. 


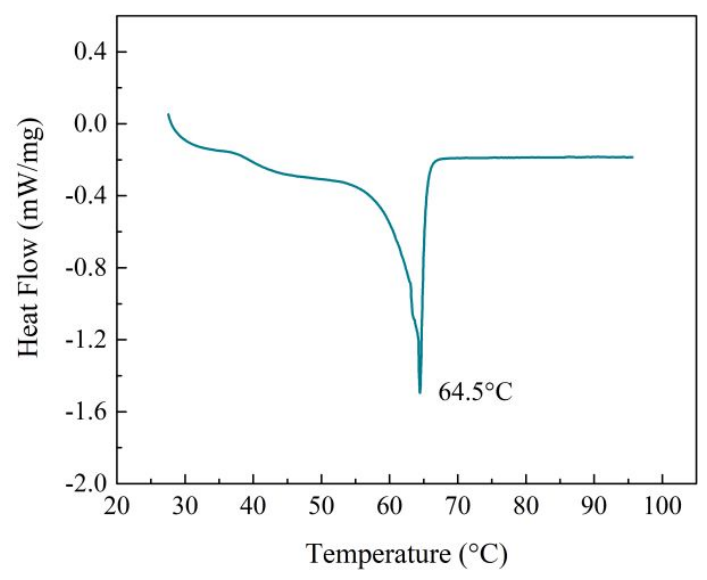

Figure S8. Melting point of 1,3,5,7-tetramethyl-adamantane.

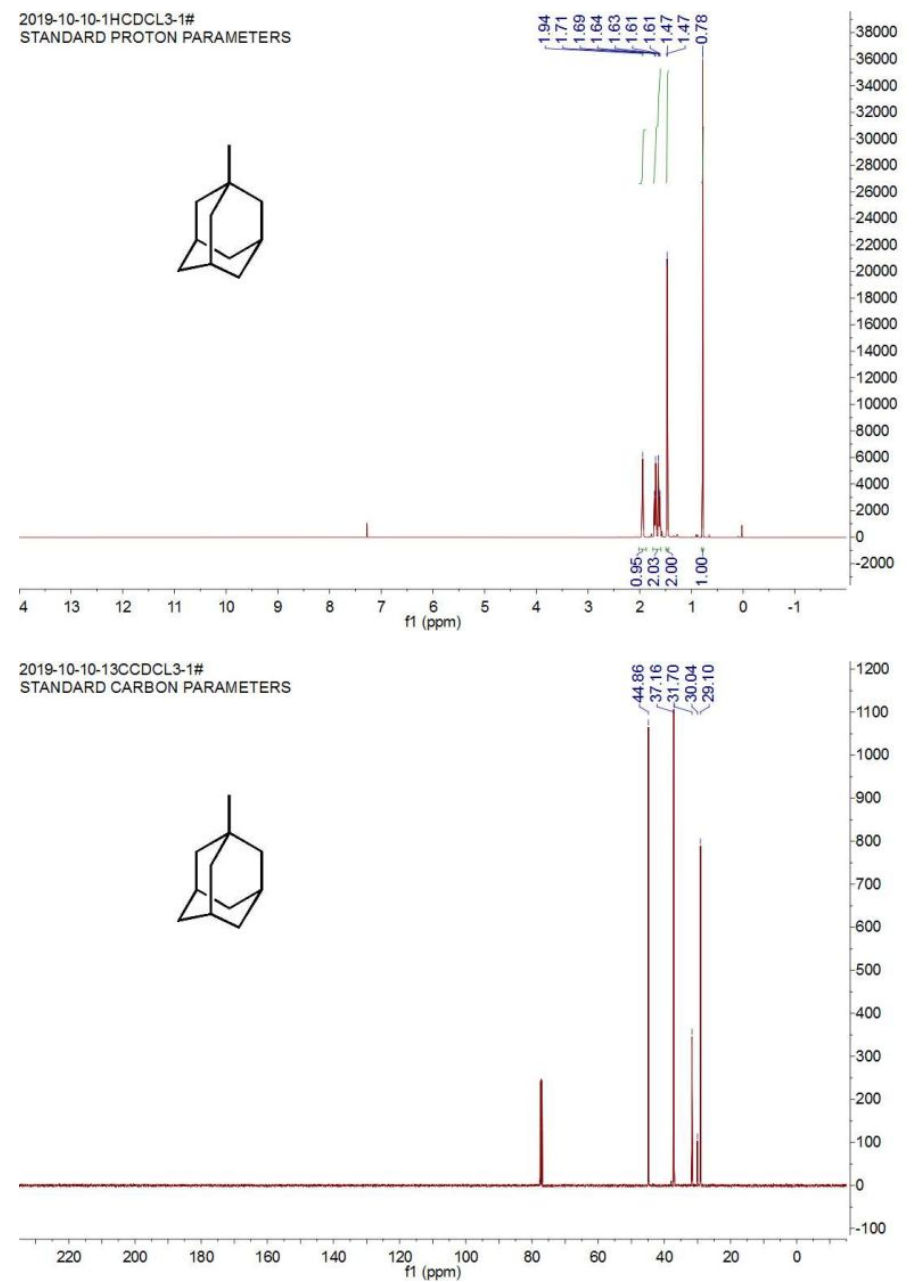

Figure S9. ${ }^{1} \mathrm{H}$ and ${ }^{13} \mathrm{C}$ NMR spectra of 1-methyl-adamantane. 


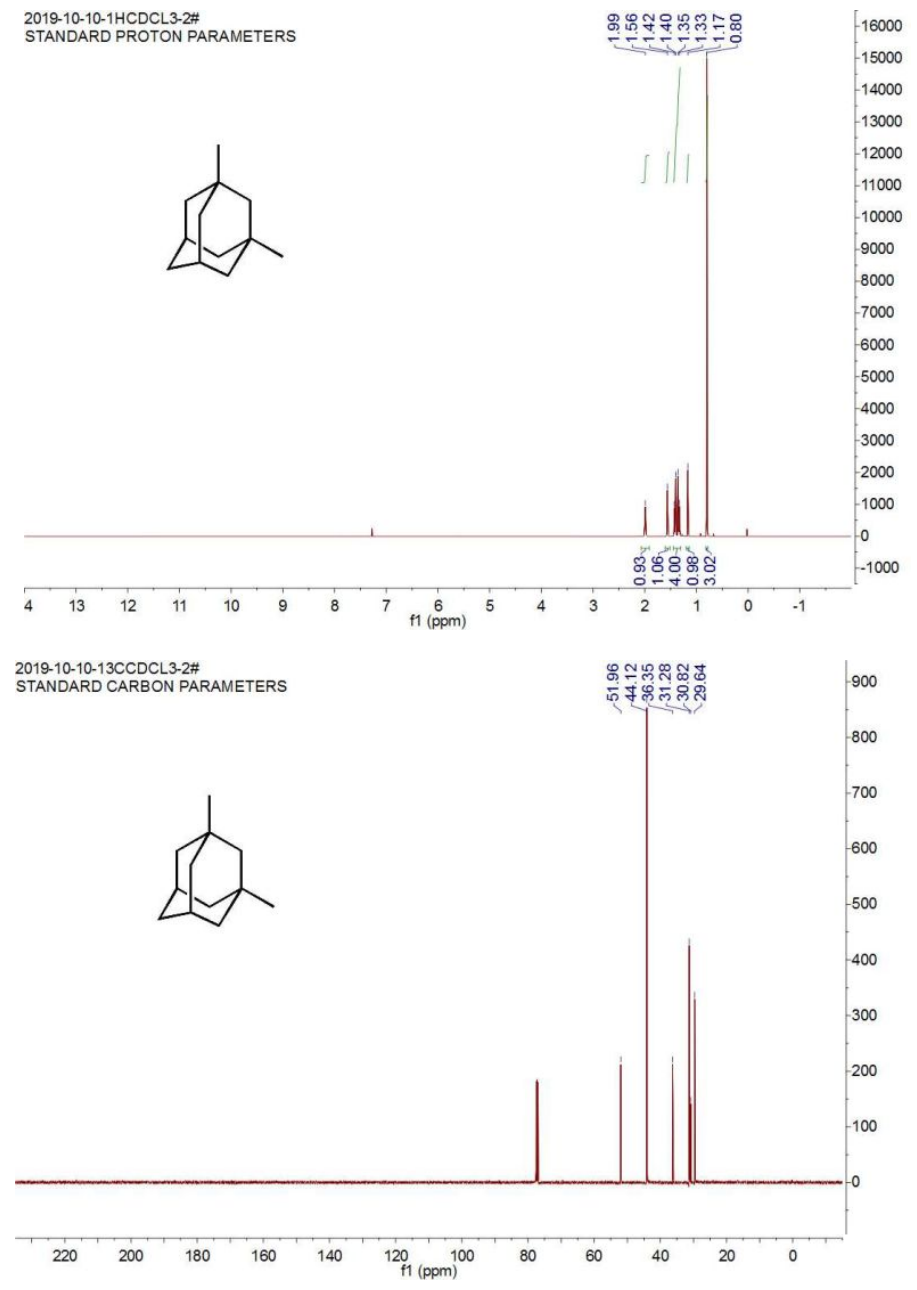

Figure S10. ${ }^{1} \mathrm{H}$ and ${ }^{13} \mathrm{C}$ NMR spectra of 1,3-dimethyl-adamantane. 